\title{
CARACTERÍSTICAS MICROBIOLÓGICAS ANTIOXIDANTES DE UM NOVO ALIMENTO FUNCIONAL PROBIÓTICO: LEITE DE OVELHA FERMENTADO POR KEFIR
}

\author{
M. S. F. LIMA ${ }^{1,3} ;$ R. A. SILVA ${ }^{2}$; M. F. SILVA ${ }^{1}$; A. L. F.PORTO ${ }^{1,2,3} ;$ M. T. \\ H.CAVALCANTI ${ }^{1,2,3}$
}

\author{
${ }^{1}$ Universidade Federal Rural de Pernambuco,Centro de Apoio à Pesquisa \\ ${ }^{2}$ Universidade Federal de Pernambuco,Laboratório de ImunopatologiaKeizoAsami \\ ${ }^{3}$ Universidade Federal Rural de Pernambuco,Departamento de Morfologia e Fisiologia \\ Animal \\ E-mail para contato: mtcvsoares@yahoo.com.br
}

\begin{abstract}
RESUMO - O leite fermentado por Kefir é conhecido por seu potencial como alimento funcional e produção de moléculas bioativas. Sendo assim, o objetivo deste trabalho foi estudar aatividade antioxidante dos peptídeos extraídos e a qualidade microbiológica do leite de ovelha fermentado por Kefir.O leite fermentado foi produzido de acordo como depósito de Patente BR 1020130158429. Aatividade antioxidante foi realizada pelos métodos ABTS e DPPH dos peptídeos hidrossolúveis.A microbiota foi investigada pela contagem de bactérias ácido-láticas e leveduras.Os extratos peptídicos testados na concentração de $6,25 \mathrm{mg} / \mathrm{mL}$ pelo método ABTS apresentaram de 16 a 41,5\% e pelo método DPPH nas concentrações de 6,25 e $3,125 \mathrm{mg} / \mathrm{mL}$ apresentaram de 27 a $72 \%$ de atividade antioxidante.Os níveis de Lactobacillusspp. eLactococcus spp. presentes na concentração de $11 \log \mathrm{UFC} / \mathrm{mL}$ e leveduras atingiram 8log $\mathrm{UFC} / \mathrm{mL}$. Este produto pode ser explorado pelas indústrias alimentares e farmacêuticas como um novo alimento funcional probiótico.
\end{abstract}

\section{INTRODUÇÃO}

A relação entre alimentação e saúde é conhecida por ser uma das chaves para a prevenção de doenças e promoção de bem-estar. Na verdade, é sobre essa base que tem havido um grande crescimento no mercado de alimentos funcionais (Farvinet al., 2010). 
Os produtos lácteos detêm uma quota importante neste mercado, haja vista que sua indústria é a que apresenta maior disponibilidade de alimentos probióticos como os iogurtes e leites fermentados. Nestes produtos são adicionadas bactérias ácido lácticas (BAL) produtoras de metabólitos secundários associados com efeitos de promoção da saúde (Mills et al., 2011).

Kefir é uma bebida fermentada, que tradicionalmente é preparado por inoculação dos grãos de kefir em leite cru. Os grãos de kefir consistem em diferentes espécies de leveduras, bactérias ácido-lácticas e bactérias ácido acéticas em uma matriz chamada kefirano. Os microorganismos presentes nos grãos de kefir vivem simbioticamente, no entanto, a composição da população pode ser diferente, tendo dependência de origem do grão, métodos e substratos utilizados para mantê-los (Grønnevik, Falstad e Narvhus, 2011).

Durante o processo fermentativo os grãos de Kefir produzem uma variedade de ingredientes que lhe dão o sabor e textura originais, além de compostos com ações bioativas. As enzimas proteolíticas dos micro-organismos envolvidos na fermentação do leite podem ser responsáveis pela liberação de certo número de peptídeos bioativos. Também é possível que os efeitos benéficos do leite fermentado para a saúde sejam aumentados pela presença desses peptídeos que são produzidos durante a fermentação e o armazenamento (Irigoyen, 2005; Papadimitriouet al., 2007).

Existem poucas informações disponíveis em relação aos leites de ovelha fermentados. Assim, o objetivo deste estudo foi investigar a atividade antioxidante dos peptídeos extraídos e a qualidade microbiológica do leite de ovelha fermentado por Kefir.

\section{MATERIAL E MÉTODOS}

\subsection{Leite de ovelha}

O leite de ovelha foi adquirido de um sítio localizado no Município de Vitória de Santo Antão-PE/Brasil, sendo a ordenha realizada de forma asséptica, o leite foi refrigerado entre $5-10^{\circ} \mathrm{C}$ e enviado ao laboratório.

\subsection{Produção de leite fermentado por grãos de Kefir}

Foi produzido de acordo com o Depósito de Patente: BR 1020130158429.

\subsection{Análises microbiológicas do leite fermentado}

O desenvolvimento da microbiota foi investigado após 1, 7, 14, 21 e 28 dias de armazenagem a $4^{\circ} \mathrm{C}$. Após a realização de diluições seriadas do leite fermentado em $0,1 \%$ de peptona em água, $100 \mu \mathrm{L}$ de três diluições foram espalhadas e semeadas em duplicata nas 
diluições $10^{7} 10^{8}$ e $10^{9}$, para bactérias e nas diluições $10^{5} 10^{6}$ e $10^{7}$ para leveduras (Miguel et al., 2010).

Para o teste presuntivo de Lactococcus spp. eLactobacillus spp. Foi utilizada a metodologia de Miguel et al. (2010) com algumas modificações, as diluições foram plaqueadas e incubadas em condições aeróbicas a pH 7 durante 2 dias a $30^{\circ} \mathrm{C}$ e a $\mathrm{pH} 5,5$ durante 5 dias a $37^{\circ} \mathrm{C}$ em condições anaeróbicas (pourplate) em Agar MRS, respectivamente.

Para a contagem de leveduras foi utilizado o método descrito por Grønnevik, Falstad e Narvhus (2011).

\subsection{Extração dos peptídeos solúveis em água (PSA)}

Os peptídeos solúveis em água foram extraídos de acordo com Pritchard, Phillips e Kailasapathy (2010). As concentrações de proteína foram determinadas usando o BCA ProteinAssay Kit (Pierce, Rockford, II, EUA). Albumina de soro bovino foi utilizada como padrão. Todas as determinações foram realizadas em triplicata.

\subsection{Ensaios de Atividade Antioxidante}

Atividade Antioxidante usando 2,2-azino-bis-(3-ethylbenzothiazoline)- 6-sulfonic acid (ABTS):Foi realizada de acordo com o método de Re et al. (1999).Para o cálculo do efeito da quantidade PSA sobre a atividade antioxidante usou-seas concentrações de 3,125, 6,25, 12,5 e $25 \mathrm{mg} / \mathrm{mL}$. As absorbâncias a $734 \mathrm{~nm}$ foram medidas em diferentes intervalos de tempo de 6 , 30, 60, 90, 150 e 180 min (Silva et al., 2012). Foi utilizado como padrão de referência o Trolox (6-hidroxi-2, ácido 5,7,8-tetrametilcroman-2-carboxílico, Sigma-Aldrich, Alemanha). Os resultados foram expressos em $\%$ de atividade antioxidante.

Atividade Antioxidante usando 1,1-diphenyl-2-picrylhydrazyl (DPPH):Em uma microplaca de 96 poços, $22 \mu \mathrm{L}$ de cada extrato, nas concentrações de $25,12,5,6,25,3,125$ $\mathrm{mg} / \mathrm{mL}$, foram misturadas com $200 \mu \mathrm{L}$ de uma solução de DPPH (25 mg/L) preparado no mesmo dia (Zubiaet al., 2009). O ácido ascórbico (Sigma-Aldrich, Alemanha) foi utilizado como padrão e resultados expressos em \% de atividade antioxidante.

\subsection{Análise estatística}

Os dados foram submetidos à análise de variância dos valores médios para as amostras individuais e comparados com nível de significância de 0,05, utilizando o software Minitab (Palo Alto, Califórnia, EUA).

\section{RESULTADOS E DISCUSÕES}




\subsection{Análises Microbiológicas do leite fermentado}

Lactobacillus e Lactococcus estavam presentes na concentração de 11 $\log _{10} \mathrm{UFC} / \mathrm{mLno}$ leite recém fermentado pelo Kefir (Figura 1), e estes resultados estão superiores aos encontrados no leite fermentado pelo Kefir da Espanha, Brasil e Noruega (Irigoyen et al., 2005; Magalhães et al., 2011; Grønnevik, Falstad e Narvhus, 2011).

Este trabalho difere dos estudos de Grønnevik, Falstad e Narvhus(2011), onde a população de Lactobacillus é maior do início ao fim do armazenamento, neste trabalho a maior população bacteriana ao $28^{\circ}$ dia de armazenamento é de Lactococcus estando de acordo com os resultados dos estudos de Irigoyenet al. (2005).

De acordo com a legislação brasileira os leites fermentados pelo Kefir devem apresentar contagem mínima de leveduras de $10^{4}$ UFC/gdurante todoseu tempo de armazenamento (BRASIL, 2000). Este trabalho está de acordo com a legislação, pois apresentou no primeiro dia de armazenamento $8 \log _{10} \mathrm{UFC} / \mathrm{mL}$ que diminuiu durante a estocagem para $6,6 \log _{10} \mathrm{UFC} / \mathrm{mLao}$ final do $28^{\circ}$ (Figura 1 ).



Figura 1-Contagem de Lactobacillus, Lactococcus e Leveduras durante o período de armazenamento.

\subsection{Extração dos peptídeos solúveis em água (PSA)}

De acordo com o a metodologia utilizada o teor protéico variou após a fermentação e ao longo do período de estocagem (Figura 2).

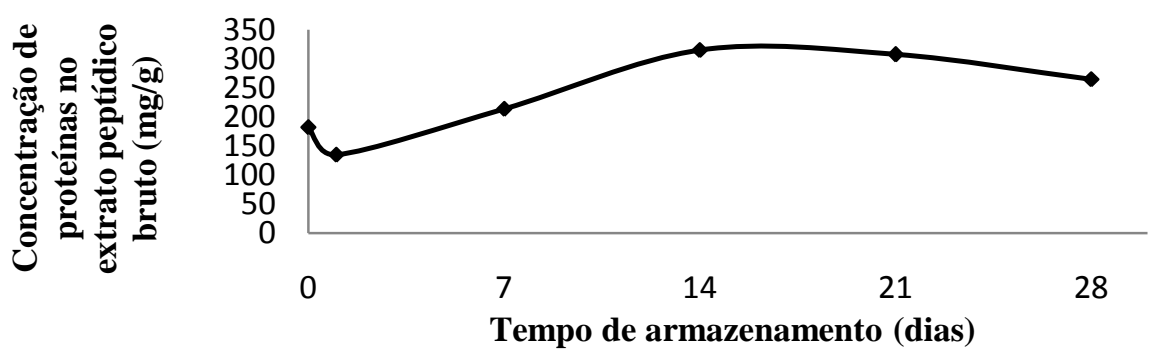


Figura 2 - Quantificação protéica do extrato peptídico bruto, antes da fermentação (0 dia) e durante o tempo de armazenamento $(1,7,14,21$ e 28 dias) do leite de ovelha fermentado por grãos de kefir.

De acordo com a figura 2, a concentração protéica aumentou do $1^{\circ}$ até o $14^{\circ}$ dia de armazenamento. Este resultado corrobora com Magalhães et al. (2011), que justificam o aumento do teor protéico durante o armazenamento pelo crescimento da biomassa microbiana e liberação de proteinases ligadas a parede celular após a lise de bactérias durante a vida de prateleira.

Do $14^{\circ}$ ao $28^{\circ}$ dia houve uma diminuição na concentração de proteínas. Isto pode ser devido a uma maior proteólise ao final das últimas semanas de armazenamento. O maior grau de proteólise ocorreu pelo metabolismo dos micro-organismos e pelo baixo $\mathrm{pH}$ (dados não mostrados), assim acontece maior liberação de peptídeos e menor detecção do número de ligações peptídicas e em conclusão menor quantificação protéica. Os dados deste estudo mostraram que tendências semelhantes das concentrações protéicas de leite de ovelha fermentado por grãos de kefir foram similares aos dados obtidos em leite de vaca e camela fermentado (Moslehishadet al., 2013).

\subsection{Atividade Antioxidante}

(ABTS): $\quad$ A Figura 3 mostra que todos os extratos peptídicos extraídos do leite de ovelha pasteurizado e do fermentado durante o período de estocagem apresentaram atividade antioxidante nas concentrações de $20,12,5,6,25$ e $3,125 \mathrm{mg} / \mathrm{mL}$. Os extratos apresentaram de 16 a $41,5 \%$ de atividade antioxidante de acordo com a metodologia utilizada. Sendo o maior valor encontrado $(41,5 \pm 3,6 \%)$ com o extrato peptídico retirado no $28^{\circ}$ dia de armazenamento do leite fermentado.

No presente estudo, a capacidade antioxidante dos peptídeos extraídos do leitefermentado não diminuiuao fim do armazenamento, com o maior valor observado aos 28 dias (Figs. 3 e 4). Isto pode ser devido à presença de micro-organismos como Lactobacillus, Lactococcus e leveduras (Grønnevik, Falstad e Narvhus, 2011) que liberam enzimas na matriz do alimento durante o tempo de armazenamento.

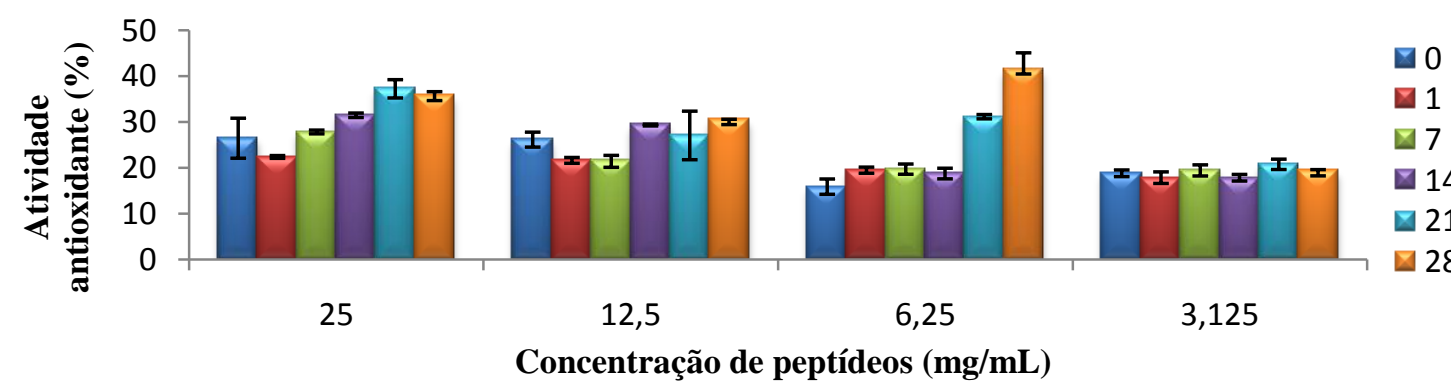


Figura 3 -Efeito da concentração do extrato peptídico aquoso do leite de ovelha pasteurizado (0) e fermentado por grãos de kefir no intervalo de (1, 7, 14, 21 e 28 dias de armazenamento) na atividade antioxidante no intervalo de $180 \mathrm{~min}$.

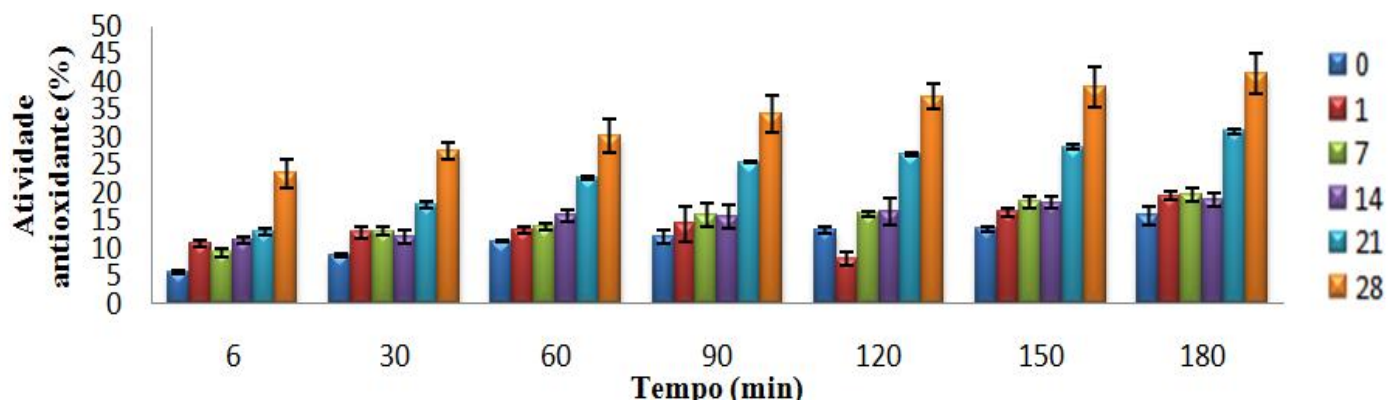

Figura 4 - Efeito do tempo de incubação na atividade antioxidante do extrato peptídico aquoso do leite de ovelha pasteurizado (0) e fermentado por grãos de kefir no intervalo de $(1,7,14$, 21 e 28 dias de armazenamento). A concentração do extrato peptídico neste estudo foi de 6 , $25 \mathrm{mg} / \mathrm{mL}$.

Meira et al. (2012) realizou o teste de atividade antioxidante utilizando o radical ABTScom extratos peptídicos aquosos de uma variedade de queijos de leite de ovelha produzidos no sul do Brasil e no Uruguai, em seus resultados perceberam que quanto maior o tempo de maturação dos queijos maior era a atividade antioxidante. Os dados acima concordam com resultados da pesquisa proposta em relação ao período de estocagem.

(DPPH): Como podem ser observados todos os extratos peptídicos testados apresentaram atividade antioxidante frente ao radical DPPH (Figura 5). Mas as concentrações que apresentaram maior capacidade antioxidante foram as amostras nas concentrações de 6,25 e $3,125 \mathrm{mg} / \mathrm{mL}$.

De acordo com os resultados deste estudo, a relação entre o período de armazenamento e atividade antioxidante não pode ser estabelecida, no entanto, a maior percentagem de atividade antioxidante foi $72,4 \pm 0,012 \%$, encontrada no extrato peptídico da amostra de leite de ovelha pasteurizado na concentração de $3,125 \mathrm{mg} / \mathrm{mL}$.

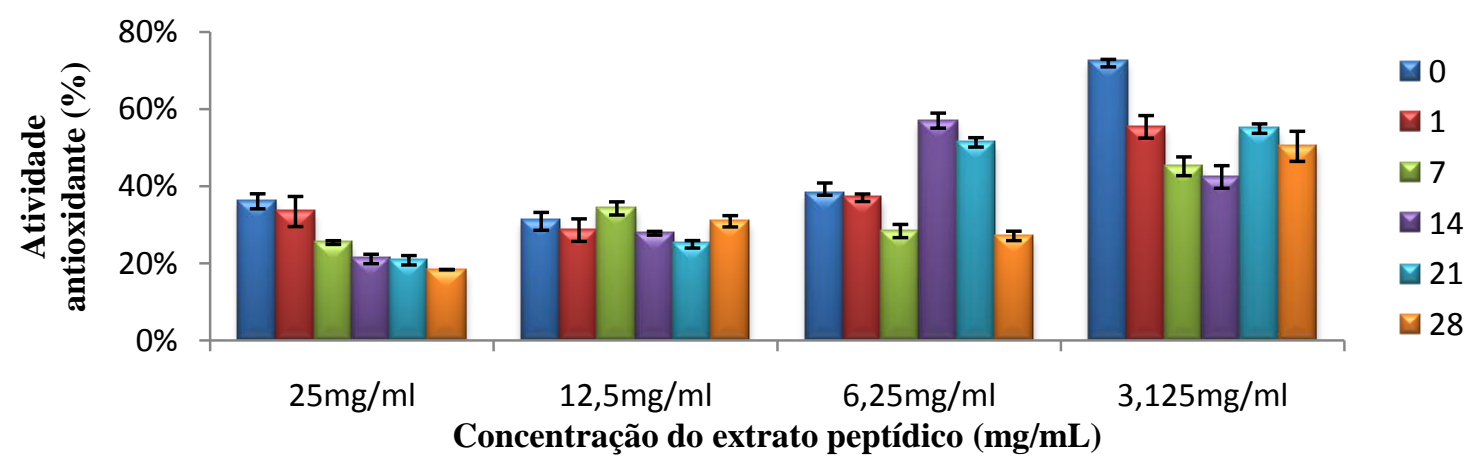


Figura 5 - Efeito da concentração do extrato peptídico aquoso do leite de ovelha pasteurizado (0) e fermentado por grãos de kefir no intervalo de (1, 7, 14, 21 e 28 dias de armazenamento) na atividade antioxidante usando o radical DPPH.

A proteólise das proteínas dos alimentos é geralmente indicada para aumentar o sequiestro do radical DPPH. No entanto, isto não é sempre observado. Pois, independente do grau de hidrólise, a substância resultante ao final do processo pode atuar como doadora de elétrons reagindo com radicais livres, convertendo-os em moléculas mais estáveis e assim terminar a reação (Corrêa et al., 2011). Isso foi observado no presente estudo, pois o extrato peptídico retirado após 28 dias de armazenamento apresentou baixas taxas de seqüestro do radical DPPH, apresentando uma das menores taxas de atividade antioxidante.

Também foi encontrada atividade antioxidante usando o radical DPPH em outros produtos lácteos fermentados. Farvinet al. (2010) estudaram a atividade antioxidante do extrato peptídico aquoso de um iogurte comercial da Dinamarca. Estes autores concluiram que o extrato peptídico bruto apresentou $94,47 \%$ de atividade antioxidante e frações derivadas dele após a separação por ultrafiltração apresentaram em média $85 \%$ de atividade antioxidante, e concluiu que tanto o extrato bruto e as frações peptídicas possuíam fortes propriedades sequestradoras do radical DPPH.

\section{CONCLUSÕES}

O leite de ovelha fermentado pelos grãos de kefir apresentou contagens de bactérias ácido láticas e leveduras dentro dos padrões estabelecidos pela legislação brasileira. $\mathrm{O}$ extrato peptídico do leite de ovelha fermentado por grãos de kefir apresentou variações no teor de proteínas entre o leite recém-fermentado e após ser estocado.Este produto apresentou características antioxidantesin vitro importantes para manutenção da saúde do consumidor, podendo ser explorado pelas indústrias alimentares e farmacêuticas como um novo alimento funcional probiótico.

\section{REFERENCIAS}

BRASIL. Resolução 5 de 13 de novembro de 2000. Padrões de identidade e qualidade de leites fermentados. Ministério da Agricultura e do Abastecimento 2000.

CORREAA, A. P. F.; DAROIT, D. J.; COELHO, J.; MEIRA, S. M. M.; LOPES, F. C.; SEGALIN, J.; RISSO, P.H.; BRANDELLI, A. Antioxidant, antihypertensive and antimicrobial properties of ovine milk caseinate hydrolyzed with a microbial protease. $J$. Sci. Food Agr., v. 91, p. 2247-2254, 2011.

FARVIN, K. H. S., BARON, C. P., NIELSEN, N. S., JACOBSEN, C. Antioxidant activity of yoghurt peptides: Part 1-in vitro assays and evaluation in $\omega$-3 enriched milk. Food Chem., v. 123, p. 1081-1089, 2010. 
GRØNNEVIK, H., FALSTAD, M., NARVHUS, J. A. Microbiological and chemical properties of Norwegian kefir during storage.Int. Dairy J., v. 21, p. 601-606, 2011.

IRIGOYEN, A., ARANA, I., CASTIELLA, M., TORRE, P., IBÁÑEZ, F. C.Microbiological, physicochemical, and sensory characteristics of kefir during storage.Food Chem.,v. 90, p. 613-620, 2005.

MAGAlHÃES, K. T., PEREIRA, G. V. M., CAMPOS, C. R., DRAGONE, G., SCHWAN, R. F. Brazilian kefir: structure, microbial communities and chemical composition. Braz. J. Microbiol.,v. 42, p. 693-702, 2011

MEIRA, S. M. M.; DAROIT, D. J.; HELFER, V. E.; CORRÊA, A. P. F.; SEGAL.IN, J.; CARRO, S.; BRANDELLI, A. Bioactive peptides in water-soluble extracts of ovine cheeses from Southern Brazil and Uruguay. Food Res Int., v. 48, p. 322 - 329, 2012.

MILLS, S.; ROSS, R. P.; HILL, C.; FITZGERALD, G. F.; STANTON, C. Milk intelligence: Mining milk for bioactive substances associated with human health. Int. Dairy J., v 21, p. 377- 401, 2011.

MOSLEHISHAD, M.; EHSANI, M. R.; SALAMI, M.; MIRDAMADI, S.; EZZATPANAH, H.; NASLAJI, A. N.; MOOSAVI-MOVAHEDI, A. A. The comparative assessment of ACEinhibitory and antioxidant activities of peptide fractions obtained from fermented camel and bovine milk by Lactobacillus rhamnosus PTCC 1637.Int. Dairy J., v. 29, p. 82-87, 2013.

PAPADIMITRIOU, C. G., VAFOPOULOU-MASTROJIANNAKI, A., SILVA, S. V., GOMES, A. M., MALCATA, F. X., ALICHANIDIS, E. Identification of peptides in traditional and probiotic sheep milk yoghurt with angiotensin I-converting enzyme (ACE)inhibitory activity. Food Chem., v.105, p. 647-656, 2007.

PRITCHARD, S.R.; PHILLIPS, M.; KAILASAPATHY, K. Identification of bioactive peptides in commercial Cheddar cheese.Food Res Int., v. 43, p. 1545-1548, 2010.

RE, R., PEllegrini, N., PROTEGGENTE, A., PANNAlA, A., YANG, M., RICEEVANS, C. Antioxidant activity applying an improved ABTS radical cationdecolorization assay.Free RadicBiol Med., v. 26, p. 1231-1237, 1999.

SILVA, R. A., LIMA, M. S. F., VIANA, J. B. M., BEZERRA, V. S., PIMENTEL, M. C. B., PORTO, A. L. F., CAVALCANTI, M. T. H., LIMA FILHO, J. L. Can artisanal "Coalho" cheese from Northeastern Brazil be used as a functional food? Food Chem., v. 135, p. 15331538, 2012.

ZUBIA, M.; FABRE, M. S.; KERJEAN, V.; LANN, K. L.; STIGER-POUVREAU, V.; FAUCHON, M.; DESLANDES, E. Antioxidant and antitumoural activities of some Phaeophyta from Brittany coasts.Food Chem, v.116, p. 693-701, 2009. 